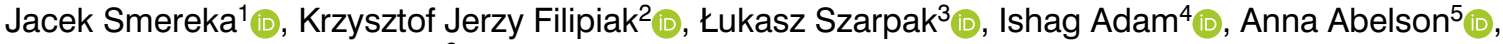
Miłosz Jarosław Jaguszewski ${ }^{6}$

${ }^{1}$ Department of Emergency Medical Service, Wroclaw Medical University, Wroclaw, Poland

$21^{\text {st }}$ Department of Cardiology, Medical University of Warsaw, Poland

${ }^{3}$ Comprehensive Cancer Center in Bialystok, Bialystok, Poland

${ }^{4}$ Department of Obstetrics and Gynecology, Unaizah College of Medicine and Medical Sciences, Qassim University, Unaizah, Saudi Arabia

${ }^{5}$ Department of Health Science, Karlstad University, Karlstad, Sweden

${ }^{6} 1^{\text {st }}$ Department of Cardiology, Medical University of Gdansk, Gdansk, Poland

\title{
Arterial hypertension and outcomes of COVID-19 - evidence from meta-analysis
}

\section{Dear Sirs,}

Since the very beginning of the COVID-19 era, studies involving over 1000 patients revealed a high percentage of arterial hypertension history in infected patients. One of the first of those included $1099 \mathrm{pa}-$ tients with confirmed COVID-19, of whom 173 had severe disease with comorbidities of hypertension $(23.7 \%)$, diabetes mellitus (16.2\%), coronary heart diseases (5.8\%), and cerebrovascular disease (2.3\%). 1 There is however no evidence that hypertension is related to outcomes of COVID-19. We, therefore, performed the meta-analysis of retrospective case series to estimate the outcome of COVID-19 patients with/without arterial hypertension history. Data from studies: Guan, et al. (2020) [1], Chen, et al. (2020) [2, 3], Wang, et al. (2020) [4], Zhou, et al. (2020) [5], Ruan, et al. (2020) [6], Du, et al. (2020) [7, 8] , Li, et al. (2020) [9], Zhang, et al. (2020) [10], Yuan, et al. (2020) [11], Wu, et al. (2020) [12] were included in the meta-analysis, as the only one is currently available after searching MEDLINE, Scopus and Web of
Science databases up to April 15, 2020. The analysis was conducted following the Preferred Reporting Items for Systematic Reviews and Meta-Analyses (PRISMA) statement. The meta-analysis showed that patients with preexisting arterial hypertension statistically significantly more often have worse clinical outcomes when infected with SARS-CoV-2 $(\mathrm{RR}=1.64 ; 95 \% \mathrm{Cl}$, 1.08-2.49; $p=0.02$ ) (Fig. 1A). In addition, statistically significant differences were observed in the incidence of hypertension in the group of deceased versus cured $(\mathrm{RR}=1.99 ; 95 \% \mathrm{Cl}, 1.63-2.41 ; \mathrm{p}<0.001)$ (Fig. 1B). This may confirm the hypothesis that arterial hypertension is one of the most important predictors affecting high morbidity and mortality of patients with COVID-19, although still the pathophysiological mechanisms are not fully understood.

\section{Conflict of interest}

The authors declare no conflict of interest. 
(A)Patents with hypertension being in severe versus nonsevere condition

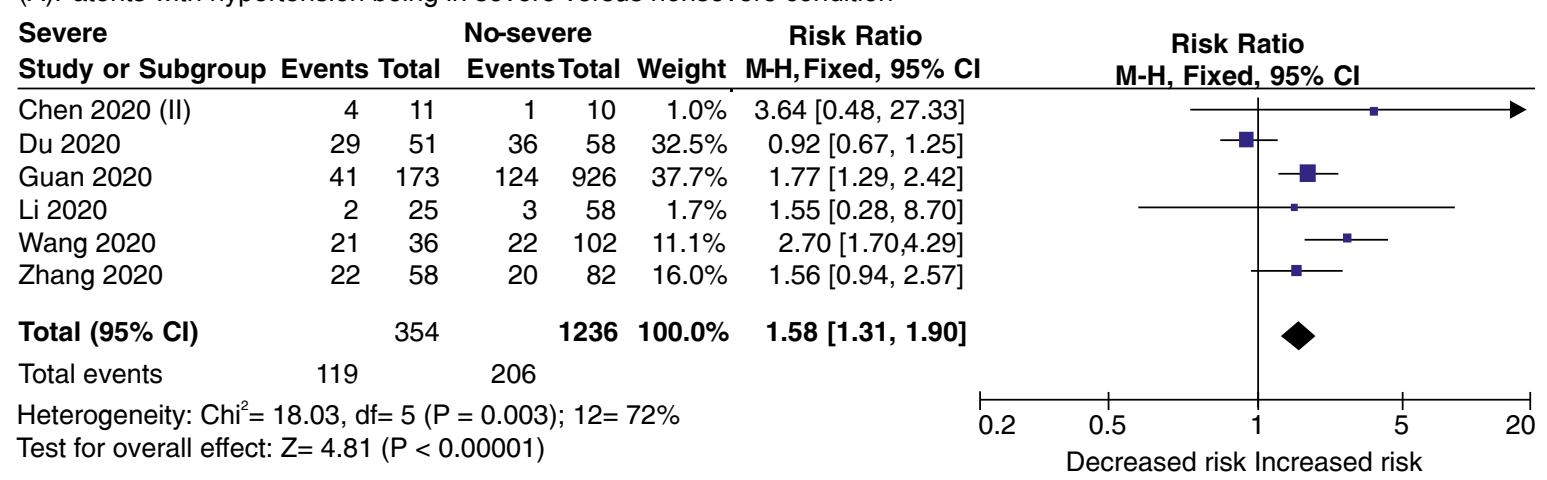

(B) Patents with hypertension decreased versus cured

\section{Decreased Cured}

Study or Subgroup Events Total Events Total Weight

\begin{tabular}{lrrrrr}
\hline Chen 2020 & 54 & 113 & 39 & 161 & $36.0 \%$ \\
Du 2020 (II) & 13 & 21 & 45 & 158 & $11.8 \%$ \\
Ruan 2020 & 29 & 68 & 23 & 82 & $23.3 \%$ \\
Wu 2020 & 16 & 44 & 7 & 40 & $8.2 \%$ \\
Yuan 2020 & 5 & 10 & 0 & 17 & $0.4 \%$ \\
Zhou 2020 & 26 & 54 & 32 & 137 & $20.2 \%$ \\
Total (95\% Cl) & & 310 & & 595 & $\mathbf{1 0 0 . 0 \%}$ \\
Total events & 143 & & 146 & &
\end{tabular}

Heterogeneity: $\mathrm{Chi}^{2}=4.01, \mathrm{df}=5(\mathrm{P}=0.55) ; 12=0 \%$

Test for overall effect: $Z=6.90(P<0.00001)$
Risk Ratio

M-H, Fixed, 95\% Cl

$1.97[1.41,2.76]$

$2.17[1.43,3.30]$

$1.52[0.98,2.37]$

$2.08[0.95,4.52]$

$18.00[1.10,294.88]$

$2.06[1.37,3.11]$

$1.99[1.63,2.41]$

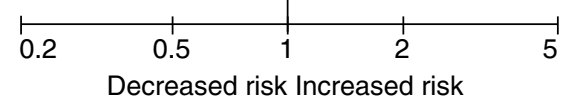

Figure 1. Forest plot of incidence of hypertension in COVID-19 patients; (A) being in severe versus no-severe condition; (B) decreased vs. cured. The center of each square represents the weighted risk ratio for individual trials, and the corresponding horizontal line stands for $95 \%$ confidence interval. The diamonds represent pooled results

\section{References}

1. Guan WJ, Ni ZY, Hu Yu, et al. China Medical Treatment Expert Group for Covid-19. Clinical Characteristics of Coronavirus Disease 2019 in China. N Engl J Med. 2020; 382(18): 1708-1720, doi: 10.1056/NEJMoa2002032, indexed in Pubmed: 32109013

2. Chen T, Wu Di, Chen H, et al. Clinical characteristics of 113 deceased patients with coronavirus disease 2019: retrospective study. BMJ. 2020; 368: m1091, doi: 10.1136/bmj.m1091, indexed in Pubmed: 32217556.

3. Chen G, Wu Di, Guo W, et al. Clinical and immunological features of severe and moderate coronavirus disease 2019. J Clin Invest. 2020; 130(5): 2620-2629, doi: 10.1172/JCl137244, indexed in Pubmed: 32217835

4. Wang D, Hu Bo, Hu C, et al. Clinical Characteristics of $138 \mathrm{Ho}$ spitalized Patients With 2019 Novel Coronavirus-Infected Pneumonia in Wuhan, China. JAMA. 2020 [Epub ahead of print], doi: 10.1001/jama.2020.1585, indexed in Pubmed: 32031570

5. Zhou F, Yu T, Du R, et al. Clinical course and risk factors for mortality of adult inpatients with COVID-19 in Wuhan, China: a retrospective cohort study. The Lancet. 2020; 395(10229): 1054-1062, doi: 10.1016/s01406736(20)30566-3.

6. Ruan Q, Yang K, Wang W, et al. Clinical predictors of mortality due to COVID-19 based on an analysis of data of 150 patients from Wuhan,
China. Intensive Care Med. 2020; 46(5): 846-848, doi: 10.1007/s00134020-05991-x, indexed in Pubmed: 32125452.

7. Du RH, Liang LR, Yang CQ, et al. Predictors of mortality for patients with COVID-19 pneumonia caused by SARS-CoV-2: a prospective cohort study. European Respiratory Journal. 2020; 55(5): 2000524, doi: 10.1183/13993003.00524-2020.

8. Du RH, Liu LM, Yin W, et al. Hospitalization and Critical Care of 109 Decedents with COVID-19 Pneumonia in Wuhan, China. Ann Am Thorac Soc. 2020 [Epub ahead of print], doi: 10.1513/AnnalsATS.202003-2250C, indexed in Pubmed: 32255382.

9. Li K, Wu J, Wu F, et al. The Clinical and Chest CT Features Associated With Severe and Critical COVID-19 Pneumonia. Invest Radiol. 2020; 55(6): 327-331, doi: 10.1097/rli.0000000000000672.

10. Zhang Jj, Dong X, Cao Yy, et al. Clinical characteristics of 140 patients infected with SARS-CoV-2 in Wuhan, China. Allergy. 2020, doi: 10.1111/all.14238.

11. Yuan M, Yin W, Tao Z, et al. Association of radiologic findings with mortality of patients infected with 2019 novel coronavirus in Wuhan, China. PLoS One. 2020; 15(3): e0230 548, doi: 10.1371/journal. pone.0230548, indexed in Pubmed: 32191764.

12. Wu C, Chen X, Cai Y, et al. Risk Factors Associated With Acute Respiratory Distress Syndrome and Death in Patients With Coronavirus Disease 2019 Pneumonia in Wuhan, China. JAMA Intern Med. 2020 [Epub ahead of print], doi: 10.1001/jamainternmed.2020.0994, indexed in Pubmed: 32167524. 